\title{
Evaluation of alternative schemes for recording body weights in meat-type quails by using random regression
}

\author{
L.P. Silva ${ }^{1}$, J.C. Ribeiro ${ }^{1}$, C.D.S. Leite ${ }^{1}$, M.F. Sousa ${ }^{1}$, C.M. Bonafé ${ }^{2}$, \\ G.C. Caetano ${ }^{1}$, A.C. Crispim ${ }^{1}$ and R.A. Torres ${ }^{1}$ \\ ${ }^{1}$ Departamento de Zootecnia, Universidade Federal de Viçosa, \\ Viçosa, MG, Brasil \\ ${ }^{2}$ Departamento de Zootecnia, \\ Universidade Federal dos Vales do Jequitinhonha e Mucuri, \\ Diamantina, MG, Brasil \\ Corresponding author: L.P. Silva \\ E-mail: luciano.pinheiro@ufv.br
}

Genet. Mol. Res. 12 (2): 1533-1539 (2013)

Received April 16, 2012

Accepted November 28, 2012

Published May 13, 2013

DOI http://dx.doi.org/10.4238/2013.May.13.6

\begin{abstract}
Data from 8759 meat-type quails from the UFV1 strain and 9128 from the UFV2 strain were used to assess the possibility of reducing the number of body weight records in genetic evaluations. The evaluated animals were weighed weekly since hatching to the 6th week of life, with up to 7 records of body weight for each bird. The data were evaluated by random regression models, with 9 alternative schemes of data recording, which included 4 records for each scheme and their covariance functions for additive and permanent environmental effects of order 3, fitting 4 intervals for residual variance, and a complete scheme, with 7 records, order of fit 6 for additive and permanent environmental effects and 7 intervals for residual variance. Estimates of heritability for body weight at
\end{abstract}


the 6th week varied from 0.45 to 0.53 for the UFV1 strain and from 0.28 to 0.54 for UFV2 strain. The schemes that had more records in points at the final extreme of the age range showed better estimates, which was likely due to certain properties of polynomial regression that led to biased results in the final extreme of the age range when data are unbalanced. The reduction of the number of body weight records taken during the growth phase is feasible, with little change to breeding value estimates, when 4 body weight records are used in random regression models.

Key words: Breeding value; Coturnix coturnix; Legendre polynomials; Runge's phenomenon

\section{INTRODUCTION}

Repeated measures taken over time, such as body weight, are longitudinal data, and require suitable methodologies to estimate genetic parameters. Meyer (2004) showed that substantial benefits could be obtained from the implementation of random regression models in meat-producing animals.

Random regression models have been suggested with the aim of facilitating these estimates, to summarize all of the estimates of animal growth parameters as a function of covariance for their random effects. In these models, any implicit information in the order and spacing of the records is utilized. Moreover, covariances of individual records are more appropriately modeled. In the context of genetic evaluation, this implies that the data are more efficiently used and their estimates of genetic values have higher accuracy, and when it comes to estimation of variance components, they facilitate the parsimonious description of changes in potentially complex covariance structures (Meyer, 2005a).

The number of measures to be taken must be decided judiciously, for not always do equidistant or sequence records provide better adjustments in polynomial functions (Atkinson et al., 2007).

Araujo et al. (2009), with simulated data, verified that random regression models are the most suitable for continuously describing the structures of covariance of growth over time and show less susceptibility to selection bias when compared with repeatability and multi-trait models.

Nobre et al. (2003), working with data on the weight of Nellore cattle, observed that the estimates of genetic parameters in random regression models were similar to those of multi-trait models, although they showed artifacts in cases of sets with missing data.

Quails have been suggested as animal models for studies of growth in poultry (Wilson et al., 1961; Martins, 2002) due to their short generation interval, high egg production, low maintenance cost, and low space requirements. Similarities between the quail and the chicken with regard to several physiological traits (Woodard et al., 1973) render the quail an interesting laboratory animal.

The objective of the present study was to estimate the efficiency of alternative schemes of data collection in meat-type quails, aiming to reduce the number of records without compromising the estimates of genetic values for selection, thus obtaining an appropriate scheme for enabling record reduction. 


\section{MATERIAL AND METHODS}

Body weight data from 8759 meat-type quails (Coturnix coturnix) from the UFV1 strain and 9128 from the UFV2 strain, from 13 generations from the Poultry Breeding Program of Universidade Federal de Viçosa, were used in this study.

All the birds were tagged with a plastic numbered band on the leg at the time of hatching and were raised on a concrete floor with bedding made of wood shavings, from the 1st to the 4th week. The animals were then selected for higher body weight at the aforementioned day, adopting, as criterion, body weight at that age. The 102 best males and the 204 best females were chosen at each generation. The selected animals were moved to controlled breeding cages. Animals were weighed weekly, from hatching to the 6th week of life, with a total of up to 7 body weight records.

A complete scheme, as a comparison parameter, was established by making use of the 7 measurements that were obtained, adjusting for polynomial functions of order 6 for additive variance and 6 for permanent environmental variance, considering 7 heterogeneity classes of residual variance, as proposed by Bonafé et al. (2011a,b).

At a later time, alternative schemes with 4 records of body weight were elaborated, using all of the possible arrangements of the records. The 1st record was the weight at hatching, the last was on the 6th week of life, and 2 records were taken at intermediate ages (Table 1). For analyses of the reduced schemes, a model of order 3 was fitted for additive variance and 3 for permanent environment, considering heterogeneous residual variance, with fitting 4 classes.

\begin{tabular}{|c|c|c|c|c|c|c|c|}
\hline Scheme & $\mathrm{W}_{0}$ & $\mathrm{~W}_{1}$ & $\mathrm{~W}_{2}$ & $\mathrm{~W}_{3}$ & $\mathrm{~W}_{4}$ & $\mathrm{~W}_{5}$ & $\mathrm{~W}_{6}$ \\
\hline Complete & $\mathrm{X}$ & $\mathrm{X}$ & $\mathrm{X}$ & $\mathrm{X}$ & $\mathrm{X}$ & $\mathrm{X}$ & $\mathrm{X}$ \\
\hline 1 & $\mathrm{X}$ & $\mathrm{X}$ & $\mathrm{X}$ & & & & $\mathrm{X}$ \\
\hline 2 & $\mathrm{X}$ & $\mathrm{X}$ & & $\mathrm{X}$ & & & $\mathrm{X}$ \\
\hline 3 & $\mathrm{X}$ & $\mathrm{X}$ & & & $\mathrm{X}$ & & $\mathrm{X}$ \\
\hline 4 & $\mathrm{X}$ & $\mathrm{X}$ & & & & $\mathrm{X}$ & $\mathrm{X}$ \\
\hline 5 & $\mathrm{X}$ & & $\mathrm{X}$ & $\mathrm{X}$ & & & $\mathrm{X}$ \\
\hline 6 & $\mathrm{X}$ & & $\mathrm{X}$ & & $\mathrm{X}$ & & $\mathrm{X}$ \\
\hline 7 & $\mathrm{X}$ & & $\mathrm{X}$ & & & $\mathrm{X}$ & $\mathrm{X}$ \\
\hline 8 & $\mathrm{X}$ & & & $\mathrm{X}$ & $\mathrm{X}$ & & $\mathrm{X}$ \\
\hline 9 & $\mathrm{X}$ & & & & $\mathrm{X}$ & $\mathrm{X}$ & $\mathrm{X}$ \\
\hline
\end{tabular}

Fixed effects of generation and sex were considered; analyses were performed through the WOMBAT software (Meyer, 2007). The model, in matrix form, is represented by:

$$
\mathrm{Y}=\mathrm{X} \beta+\mathrm{Z}_{1} \mathrm{a}+\mathrm{Z}_{2} \mathrm{p}+\mathrm{e}
$$

where $Y=$ vector of observations; $X=$ incidence matrix of fixed regression coefficients of order 3; $Z_{1}=$ incidence matrix of direct additive random regression coefficients; $Z_{2}=$ incidence matrix of permanent environmental random regression coefficients; $\beta=$ vector of fixed effects; $a=$ vector of direct additive random regression coefficients; $p=$ vector of permanent environmental random regression coefficients; and $e=$ vector of residuals. 
Assuming

$$
\left[\begin{array}{l}
\mathrm{a} \\
\mathrm{p} \\
\mathrm{e}
\end{array}\right] \sim N(0, \mathrm{~V}), \mathrm{V}=\left[\begin{array}{ccc}
K_{a} \otimes \mathrm{A} & 0 & 0 \\
0 & K_{p} \otimes \mathrm{I} & 0 \\
0 & 0 & R
\end{array}\right]
$$

where $K_{a}=$ matrix of (co)variances between the additive random regression coefficients; $A=$ numerator relationship matrix between animals; $K_{p}=$ matrix of (co)variances between the permanent environment random regression coefficients; $I=$ an identity matrix; and $R=$ diagonal matrix of residual variances with elements that depend on the number of classes fitted.

For every alternative scheme, the breeding value of the animals from the last (13th) generation available on the database was evaluated in the 6th week, and was compared with the values predicted by the complete model. The 6th week of age was chosen as a criterion since it is the age at which slaughter is commonly employed in the industry, and the use of predicted breeding values was considered to correct for fixed effects and for additional random effects in each individual record.

The following indicators of quality of the models were used to compare the breeding values of the alternative against the complete scheme:

Mean squared prediction error (MSPE): $\frac{1}{n} \sum_{i=1}^{n}\left(\hat{y}_{i}-y_{i}\right)^{2}$

(Equation 3)

Percentage squared bias (PSB): $\left(\sum_{i=1}^{n}\left(\hat{y}_{i}-y_{i}\right)^{2} / \sum_{i=1}^{n}\left(y_{i}\right)^{2}\right) x 100$

(Equation 4)

Mean absolute deviation (MAD): $\frac{1}{n} \sum_{i=1}^{n}\left|y_{i}-y_{i}\right|$

(Equation 5)

Simple correlation $(\mathrm{r}): \operatorname{COV}\left(\hat{y}_{i}, y_{t}\right) / \sqrt{V\left(\hat{y}_{t}\right) V\left(y_{i}\right)}$;

(Equation 6)

where $y_{i}=$ breeding value on day $i$, known with the complete scheme; $\hat{y}_{i}=$ breeding value on day $i$, estimated with the alternative scheme; and $n=$ number of records in the alternative scheme.

\section{RESULTS AND DISCUSSION}

The higher number of measurements in each strain was for weight at hatching, with little reduction in further weighings, with only $86 \%$ of records remaining for strain UFV1 and $82 \%$ for UFV2 for the weights at the 6 th week (Tables 2 and 3). These losses were due to mortality and losses of tagged animals throughout their growth period.

Table 2. Descriptive statistics for the UFV1 strain.
\begin{tabular}{lcccrr}
\hline & Number of records & Mean & Standard deviation & Minimum & Maximum \\
\hline $\mathrm{W}_{0}$ & 8759 & 9.69 & 1.08 & 5.30 & 13.42 \\
$\mathrm{~W}_{1}$ & 8540 & 33.31 & 7.48 & 10.00 & 58.03 \\
$\mathrm{~W}_{2}$ & 8368 & 86.14 & 16.14 & 12.79 & 136.69 \\
$\mathrm{~W}_{3}$ & 8532 & 149.15 & 24.70 & 44.80 & 228.85 \\
$\mathrm{~W}_{4}$ & 8533 & 210.06 & 29.67 & 81.00 & 315.06 \\
$\mathrm{~W}_{5}$ & 7867 & 248.81 & 31.61 & 109.01 & 397.68 \\
$\mathrm{~W}_{6}$ & 7574 & 274.29 & 36.72 & 131.27 & 448.54 \\
\hline $\mathrm{W}_{0}$ to $\mathrm{W}_{6}=$ body weight from hatch to 6th week, in grams.
\end{tabular}




\begin{tabular}{|c|c|c|c|c|c|}
\hline & Number of records & Mean & Standard deviation & Minimum & Maximum \\
\hline $\mathrm{W}_{0}$ & 9128 & 9.82 & 1.13 & 5.60 & 13.55 \\
\hline $\mathrm{W}_{1}^{0}$ & 8925 & 33.91 & 6.84 & 11.80 & 59.36 \\
\hline $\mathrm{W}_{2}^{1}$ & 8627 & 87.46 & 15.95 & 20.30 & 214.20 \\
\hline $\mathrm{W}_{3}^{2}$ & 8793 & 151.20 & 23.95 & 39.00 & 265.00 \\
\hline $\mathrm{W}_{4}^{3}$ & 8811 & 213.01 & 28.52 & 78.00 & 358.17 \\
\hline $\mathrm{W}_{5}^{4}$ & 8183 & 255.65 & 31.17 & 104.01 & 396.67 \\
\hline $\mathrm{W}_{6}^{3}$ & 7486 & 283.54 & 37.42 & 123.18 & 429.62 \\
\hline
\end{tabular}

$\mathrm{W}_{0}$ to $\mathrm{W}_{6}=$ body weight from hatch to 6 th week, in grams.

The phenotypic variances in the UFV1 strain for weight at the 6th week were similar in all schemes, varying from 1063.88 to 1127.89 , as well as their heritability values, which varied between 0.45 and 0.53 (Table 4). Most of higher heritability estimates, in both strains, were observed in schemes 4,7 , and 9 , likely due to these having the greatest numbers of records. The indicators of quality of the models indicated that the values were more similar to the complete scheme.

\begin{tabular}{|c|c|c|c|c|}
\hline Scheme & $\mathrm{h}^{2}$ & $\mathrm{pe}^{2}$ & $\sigma_{p}^{2}$ & $\mathrm{SE}$ \\
\hline Complete & 0.45 & 0.33 & 1069.32 & 19.28 \\
\hline 1 & 0.47 & 0.52 & 1072.12 & 20.30 \\
\hline 2 & 0.47 & 0.53 & 1076.33 & 20.15 \\
\hline 3 & 0.50 & 0.32 & 1096.79 & 20.91 \\
\hline 4 & 0.53 & 0.23 & 1125.43 & 21.36 \\
\hline 5 & 0.48 & 0.29 & 1080.66 & 20.46 \\
\hline 6 & 0.48 & 0.26 & 1063.88 & 19.80 \\
\hline 7 & 0.52 & 0.20 & 1127.89 & 21.41 \\
\hline 8 & 0.47 & 0.24 & 1077.96 & 20.32 \\
\hline 9 & 0.48 & 0.24 & 1092.67 & 19.99 \\
\hline
\end{tabular}

For the UFV2 strain, the variance ranged from 1148.72 to 1218.53 , similarly to that obtained in the complete model, although the heritability values had greater variation than that of the adopted model, varying from 0.28 to 0.54 (Table 5 ).

\begin{tabular}{|c|c|c|c|c|}
\hline Scheme & $\mathrm{h}^{2}$ & $\mathrm{pe}^{2}$ & $\sigma_{p}^{2}$ & SE \\
\hline Complete & 0.37 & 0.41 & 1172.45 & 20.20 \\
\hline 1 & 0.35 & 0.64 & 1148.72 & 21.59 \\
\hline 2 & 0.38 & 0.46 & 1164.90 & 20.34 \\
\hline 3 & 0.39 & 0.32 & 1183.70 & 21.59 \\
\hline 4 & 0.54 & 0.20 & 1208.89 & 23.52 \\
\hline 5 & 0.28 & 0.44 & 1172.37 & 20.78 \\
\hline 6 & 0.35 & 0.40 & 1190.69 & 21.65 \\
\hline 7 & 0.44 & 0.25 & 1218.53 & 23.49 \\
\hline 8 & 0.35 & 0.30 & 1151.16 & 21.35 \\
\hline 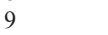 & 0.40 & 0.30 & 1187.71 & 22.49 \\
\hline
\end{tabular}


Among the schemes that presented the best indicators of quality (lower MSPE, PSB, and $\mathrm{MAD}$, and higher correlation) are those that included the weight measurement taken at the 5 th week (schemes 4, 7, and 9), which was likely due to the presence of more records at the end of the age range and also the proximity to the last record, thus generating better estimates of genetic parameters (Table 6). This may also be due to the greater difficulty related to the properties of polynomial regression, which does not fit well at the extremes of age range and with the fitting order used to describe the data (Arango et al., 2004).

Table 6. Mean squared prediction error (MSPE), percentage squared bias (PSB), mean absolute deviation (MAD), and simple correlation ( $r$ ) of alternative schemes with complete scheme for the UFV1 strain.

\begin{tabular}{lrrrr}
\hline Scheme & MSPE & PSB & MAD & r \\
\hline 1 & 129.13 & 8.52 & 0.96 & 0.44 \\
2 \\
2 & 119.81 & 7.91 & 1.80 & 0.86 \\
3 & 87.84 & 5.80 & 1.80 & \\
4 & 53.53 & 3.53 & 7.18 & \\
5 & 173.86 & 11.48 & 2.28 & 0.91 \\
6 & 135.60 & 8.95 & 3.27 & 0.86 \\
7 & 51.17 & 3.38 & 2.98 & 0.96 \\
8 & 99.78 & 6.59 & 1.58 & 0.90 \\
9 & 18.30 & 1.21 & & 0.99 \\
\hline
\end{tabular}

The uniform spacing of the data may not provide the best results for the fitting of the polynomial function, as there is the so-called "Runge's phenomenon", which describes the errors of a polynomial approximation and explains that these errors occur primarily at the extremes of the age range (de Boor, 2001). Therefore, it is expected that models that utilize polynomial functions with little information at later ages rather than at initial ages present erratic and implausible estimates of variance components and genetic parameters (Meyer, 2005b).

Schemes that used lower numbers of body weight values at the end of the age range, such as models 1, 2, and 5, presented higher MSPE, PSB, and MAD and lower correlations of genetic values relative to the complete model. These results can be attributed to the lower number of records at the final approximation of the age range, which might hamper the partition of total variance in the correct proportions for each random effect (Sousa et al., 2008).

For the UFV2 strain, the results were quite similar (Table 7), with the best indicators for the schemes with more information at the extreme end of the age range, although closest to the estimated values compared to the complete scheme. The difference in the indicator values for this strain was larger between schemes with or without the record at the 5th week, thus reinforcing the importance of this record for a more accurate estimate of genetic values.

Table 7. Mean squared prediction error (MSPE), percentage squared bias (PSB), mean absolute deviation (MAD), and simple correlation (r) of alternative schemes with complete scheme for the UFV2 strain.

\begin{tabular}{lrlrr}
\hline Scheme & MSPE & PSB & MAD & \multicolumn{1}{c}{ r } \\
\hline 1 & 194.97 & 3.22 & 10.79 & 0.87 \\
2 & 114.16 & 1.88 & 3.62 & 0.88 \\
3 & 76.47 & 1.26 & 1.01 & 0.89 \\
4 & 25.27 & 0.42 & 7.04 & 0.96 \\
5 & 114.08 & 1.88 & 3.64 & 0.89 \\
6 & 76.15 & 1.26 & 1.70 & 0.89 \\
7 & 21.85 & 0.36 & 3.70 & 0.97 \\
8 & 75.82 & 1.25 & 0.03 & 0.89 \\
9 & 4.60 & 0.07 & & 0.99 \\
\hline
\end{tabular}


The reduction in the number of weighings of meat-type quails during the growth phase is feasible, and the estimates of genetic values are relatively unaltered when 4 records of body weight are analyzed by random regression models. The scheme that best predicts the breeding value at the 6th week, using random regression models, is one that includes the records taken at hatching and at the 4 th, 5 th, and 6 th weeks.

\title{
ACKNOWLEDGMENTS
}

\author{
Research supported by CNPq, INCT-CA, and Fapemig.
}

\section{REFERENCES}

Arango JA, Cundiff LV and Van Vleck LD (2004). Covariance functions and random regression models for cow weight in beef cattle. J. Anim. Sci. 82: 54-67.

Araujo SI, Regazzi AJ, Araujo CV, Cruz CD, et al. (2009). Variance component estimation with longitudinal data: a simulation study with alternative methods. Crop Breed. Appl. Biotech. 9: 202-209.

Atkinson AC, Donev AN and Tobias RD (2007). Optimum Experimental Designs, with SAS. 1st edn. Oxford University Press, Oxford.

Bonafé CM, Torres RA, Sarmento JLR, Silva LP, et al. (2011a). Modelos de regressão aleatória para descrição da curva de crescimento de codornas de corte. Rev. Bras. Zootec. 40: 765-771.

Bonafé CM, Torres RA, Teixeira RB, Silva FG, et al. (2011b). Heterogeneidade de variância residual em modelos de regressão aleatória na descrição do crescimento de codornas de corte. Rev. Bras. Zootec. 40: 2129-2134.

de Boor C (2001). A Practical Guide to Splines. Springer Series in Applied Mathematics. 2nd edn. Springer Verlag, New York.

Martins EN (2002). Perspectivas do Melhoramento Genético de Codornas no Brasil. Anais do IV Simpósio Nacional de Melhoramento Animal, Campo Grande.

Meyer K (2004). Scope for a random regression model in genetic evaluation of beef cattle for growth. Livest. Prod. Sci. 86: 69-83.

Meyer K (2005a). Advances in methodology for random regression analyses. Aust. J. Exp. Agr. 45: 847-858.

Meyer K (2005b). Random regression analyses using B-splines to model growth of Australian Angus cattle. Genet. Sel. Evol. 37: 473-500.

Meyer K (2007). WOMBAT: a tool for mixed model analyses in quantitative genetics by restricted maximum likelihood (REML). J. Zhejiang Univ. Sci. B 8: 815-821.

Nobre PR, Misztal I, Tsuruta S, Bertrand JK, et al. (2003). Analyses of growth curves of nellore cattle by multiple-trait and random regression models. J. Anim. Sci. 81: 918-926.

Sousa JER, Silva MA, Sarmento JLR, Sousa WH, et al. (2008). Homogeneidade e heterogeneidade de variância residual em modelos de regressão aleatória sobre o crescimento de caprinos Anglo-Nubianos. Pesq. Agropec. Bras. 43: 17251732.

Wilson WO, Abbott UK and Abplanalp H (1961). Evaluation of Coturnix (Japanese Quail) as pilot animal for poultry. Poultry Sci. 40: 651-657.

Woodard AE, Abplanalp H and Wilson WO (1973). Japanese Quail Husbandry in the Laboratory (Coturnix Coturnix Japonica). Department of Avian Sciences. University of California, Davis. 